Arq. Bras. Med. Vet. Zootec., v.67, n.6, p.1563-1571, 2015

\title{
Perfil clínico e microbiológico de cães com e sem otoacaríase
}

[Clinical and microbiological profile of dogs with and without otoacariasis]

\author{
C.P. Souza, M.M.S. Souza, F.B. Scott
}

Universidade Federal Rural do Rio de Janeiro - Seropedica, RJ

\begin{abstract}
RESUMO
Os objetivos do estudo foram identificar a presença de microrganismos nos condutos auditivos dos cães através dos exames citológico e microbiológico, assim como avaliar a associação destes à otoacaríase e seus sinais clínicos. O diagnóstico da infestação por Otodectes cynotis foi realizado através de otoscopia bilateral e pela coleta de material e visualização do parasito sob microscópio esterioscópico, constituindo o exame parasitológico. Outras coletas de secreção otológica de cada orelha foram realizadas para confecção de lâminas para a citologia e para o isolamento microbiológico, sendo este último material coletado através de "swab" estéril. Dos 250 animais examinados, em $15(6 \%)$ foi identificado o ácaro $O$. cynotis. Observou-se associação entre a presença do parasito e a ocorrência de otite clínica externa caracterizada especialmente por eritema auricular $(\mathrm{P}<0,001)$ e a produção excessiva de secreção otológica $(\mathrm{P}=0,0016)$, assim como a observação, pelos proprietários, de prurido ótico nos cães $(\mathrm{P}<0,001)$. Sugerese a possibilidade de essas associações serem efeito da infestação. Houve também a associação $(\mathrm{P}<0,01)$ entre a otoacaríase e a ocorrência de microrganismos nos dois condutos auditivos de cada animal, detectados através da citologia. No entanto, não houve associação $(\mathrm{P}=0,04 \mathrm{e} \mathrm{p}=0,07)$ entre a presença do ácaro $O$. cynotis e a ocorrência de microrganismos no exame microbiológico das orelhas direita e esquerda, respectivamente.
\end{abstract}

Palavras-chave: cão, Otodectes cynotis, otite externa

\begin{abstract}
The goals of this study were to identify microorganisms in dogs' ear canals through cytological and microbiological examination, and evaluate their association with otoacariasis and its clinical signs. Otodectes cynotis infestation diagnosis was achieved by bilateral otoscopy, and by parasite viewing on cerumem under stereoscopic microscope, representing the parasitological exam. Ear discharge was also collected from each canal to fix cytology slides and for microbiological isolation, but this last sample was collected with sterile swab. Among the 250 studied animals, 15 (6\%) had ear mites. There was an association between the parasite and external clinical otitis specially as established by auricular erythema $(P<0,001)$ and excessive production of ear discharge $(P=0,0016)$, as well as ear pruritus observed by the owners $(P<0,001)$. It has been suggested that these associations can be an effect of the infestations. There was also an association $(P<0,01)$ between otoacariasis and microorganisms detected by cytological exam in both ear canals of each dog. However, there was no association $(P=0,04 e$ $P=0,07)$ between the presence of ear mite and microorganisms detected by microbiological exam of right and left ears.
\end{abstract}

Keywords: dog, Otodectes cynotis, external otitis

Recebido em 29 de julho de 2014

Aceito em 23 de junho de 2015

E-mail: clarissaps@globo.com 


\section{INTRODUÇÃO}

O conduto auditivo dos cães é um ambiente frágil onde mudanças no microclima podem alterar o delicado equilíbrio da secreção normal e da microflora, resultando em infecções oportunistas que podem perpetuar um processo inflamatório subjacente (August, 1988).

A otite externa no cão é uma doença multifatorial que pode acometer até $20 \%$ dos animais consultados na rotina clínica. Os fatores causadores da otopatia são classificados como: predisponentes, primários, secundários e perpetuantes (Saridomichelakis et al., 2007).

Fatores predisponentes são alterações anatômicas e fisiológicas, como formato da orelha, excesso de pelos e neoplasias. Já os primários são representados por dermatopatias do revestimento epitelial do conduto auditivo, como alergias, distúrbios de queratinização e doenças autoimunes, assim como a presença de corpos estranhos e ectoparasitos. Esses fatores primários podem iniciar uma inflamação e esta ser intensificada pelos fatores secundários, as infecções bacterianas e fúngicas. Ainda de acordo com a cronicidade das alterações, podem ocorrer os fatores perpetuantes, que são mudanças permanentes do conduto auditivo, membrana timpânica e orelha média (Gotthelf, 2007; Saridomichelakis et al., 2007; Oliveira et al., 2012).

A infestação por Otodectes cynotis, também denominada otocaríase ou sarna otodécica, é uma otopatia parasitária comum em várias espécies de carnívoros, especialmente cães e gatos. Esse ácaro é bem ativo e passa todo o ciclo de vida dentro do conduto auditivo de seus hospedeiros, sendo frequentemente incriminado como causa de desconforto, prurido e desencadeamento de otites externas (Curtis, 2004).

O diagnóstico de otopatias em cães é realizado através dos históricos dos animais, da avaliação da orelha externa através da otoscopia, e de exames complementares, como a citologia e cultura. Em alguns casos ainda são utilizados exames de imagem (Oliveira et al., 2012).

Os ácaros O. cynotis podem ser detectados através da otoscopia, vídeo-otoscopia ou exame parasitológico do cerumem (Souza et al., 2004; Souza et al., 2013). Já o exame citológico oferece importante informação sobre a quantidade e a participação dos microrganismos nas otopatias, enquanto a cultura os identifica e ainda possibilita a execução de testes para determinação do tratamento adequado (Ginel et al., 2002; Tater et al., 2003). Os microrganismos mais frequentemente isolados do conduto auditivo de cães são Staphylococcus intermedius e Malassezia pachydermatis, embora vários outros também já tenham sido descritos (Oliveira et al., 2008).

Objetivou-se identificar os microrganismos presentes nos condutos auditivos dos cães através dos exames citológico e microbiológico, e avaliar a associação à otoacaríase e seus sinais clínicos.

\section{MATERIAL E MÉTODOS}

Foram avaliados 250 cães atendidos no Setor de Dermatologia do Hospital Veterinário de Pequenos Animais da Universidade Federal Rural do Rio de Janeiro, independentemente de o proprietário apresentar queixas relacionadas a problemas nas orelhas dos cães ou de os animais demonstrarem sinais clínicos associados a otopatias.

O diagnóstico de otite externa foi baseado nos sinais clínicos e na avaliação otoscópica das orelhas dos cães. Também foi observada a presença e tipo de secreção otológica, classificadas como: amarelada, esverdeada, marrom ou purulenta (Chickering, 1988). A presença ou não de prurido ótico foi determinada de acordo com a percepção do proprietário.

O ácaro O. cynotis foi detectado também através da otoscopia bilateral dos condutos auditivos, assim como na observação da secreção otológica coletada por um pinça de dissecção com algodão em sua ponta, e posteriormente examinada em microscópio esterioscópico, constituindo assim o diagnóstico parasitológico (Foley, 1991; Souza et al., 2013).

A partir das secreções otológicas examinadas, foram confeccionadas lâminas com o conteúdo de cada orelha para exame citológico. Estas foram coradas por panótico rápido (Instant Prov), para observação de células de 
descamação, inflamatórias, bactérias e leveduras que pudessem estar presentes nos condutos auditivos. As células morfologicamente semelhantes foram contadas, considerando-se o escore determinado por Nobre et al. (1998), em que determinam: (negativo) ausência de células, (+) 1 a 5 células por campo em objetiva de imersão, (++) de 6 a 10 células por campo em objetiva de imersão e $(+++)$ mais de 10 células por campo em objetiva de imersão.

Amostras de secreção de cada um dos 500 condutos auditivos foram coletadas através de "swab" estéril impregnado em alginato de sódio $\left(\mathrm{DME}^{\circledR}\right)$ e encaminhadas para isolamento bacteriano e fúngico no Laboratório de Microbiologia da Universidade Federal Rural do Rio de Janeiro. O isolamento bacteriano consistiu em inoculação primária em Ágar Sangue de Carneiro e Ágar Infusão de Cérebro e Coração (BHI), onde as colônias, previamente analisadas pelo método de Gram e prova da catalase, foram repicadas em meios seletivos e diferenciais e posteriormente submetidas aos testes bioquímicos pertinentes para caracterização de gênero e espécies de acordo com Koneman et al. (2008). Para análise fúngica, as amostras foram semeadas em ágar Sabouraud dextrose acrescido de cloranfenicol $(200 \mathrm{mg} / \mathrm{l})$ para estabelecimento de meio seletivo para isolamento de fungos leveduriformes. Foram incubadas em estufa BOD a $25^{\circ} \mathrm{C}$ por período de até 7 dias, com leituras diárias a partir das primeiras 48 horas. A identificação foi efetuada com baseada nas características morfológicas dos ciclos anamorfos dos agentes conforme preconiza Hoog et al 2000.

As variáveis otite clínica, prurido, secreção otológica e microrganismos foram testadas como variáveis desfecho, como consequência da infestação pelo ácaro, que foi considerado de exposição.

As associações entre as variáveis consideradas de exposição e a variável que representa o desfecho ou efeito foram avaliadas pelo teste do $\mathrm{X}^{2} \mathrm{e}$, quando necessária, foi utilizada a correção pelo Fisher exato, com auxílio do programa EPI INFO 2002 - CDC 2003.

\section{RESULTADOS E DISCUSSÃO}

Dos 250 animais examinados, em 15 (6\%) foi identificada a presença do ácaro $O$. cynotis através do exame parasitológico, sendo que em 4 $(1,6 \%)$ foi observada infestação apenas na orelha direita, em $2(0,8 \%)$, somente na esquerda, e em $9(3,6 \%)$, infestação bilateral.

O ácaro $O$. cynotis se alimenta de restos epidérmicos e fluidos teciduais, causando uma irritação mecânica que leva a alterações nos condutos auditivos dos cães. Dentre os 15 animais infestados, $13(86,7 \%)$ apresentavam sinais clínicos de otite externa, especialmente eritema, tanto na orelha direita como na esquerda. Também foi obervado que, dentre os 235 cães sem otoacaríase, 106 apresentavam alterações clínicas na orelha direita e 104 na esquerda, por outras causas não parasitárias.

Observou-se associação $(\mathrm{p}<0,001)$ entre a ocorrência de otite clínica externa e a presença do ácaro, e também houve associação $(\mathrm{p}=0,0016$ e $p=0,0013$ ) entre a ocorrência de alterações clínicas nas orelhas direitas e esquerdas, respectivamente.

Estes resultados são semelhantes a relatos anteriores em que os autores comentam sobre a possibilidade de os ácaros causarem uma otite externa irritante, acarretando sinais clínicos, como eritema, roçar e sacudir da cabeça, otalgia, prurido e eventualmente erosões do epitélio do conduto auditivo (Kwochka, 1987; Sosna e Medleau, 1992; Curtis, 2004). Entretanto diferentes observações foram relatadas por Gomes et al. (1998), que estudaram cães com otoacaríase, mas sem alterações clínicas que pudessem ser associadas à presença do ácaro; assim como por Larsson (1989), que também sugere que $O$. cynotis pode ser encontrado em condutos auditivos hígidos, e aventou a possibilidade de o ácaro apenas causar manifestações clínicas em animais com hipersensibilidade.

O ácaro O. cynotis é muito ativo dentro dos condutos auditivos dos animais parasitados, causando grande incômodo, o que acarretaria o prurido. Dentre os 15 animais com sarna otodécica, $12(80 \%)$ apresentavam prurido nas orelhas. Outros 61 cães não parasitados exibiam 
prurido ótico, o que nos mostra que outras causas de otite clínica também são pruriginosas.

A análise desses dados revelou uma associação $(\mathrm{p}<0,001)$ entre o parasito e o prurido. Vários autores, como Foley (1991) e Miller et al. (2013), vêm relatando a presença de prurido ótico nos animais infestados pelo ácaro $O$. cynotis. Ainda resultados semelhantes aos do presente estudo foram encontrados por Larsson (1989), que descreve $85,7 \%$ de cães examinados com otite externa parasitária apresentando prurido.

Não foram encontrados animais infestados pelo ácaro $O$. cynotis que apresentassem otohematoma. Mas a literatura consultada relata ser frequente a observação dessa alteração em animais com sarna otodécica, como nos relatos de Medleau e Hnilica (2003) e Gotthelf (2007). Estes sugeriram que o prurido gera lesões cutâneas nas regiões auriculares e periauriculares, muitas vezes havendo formação dessas coleções líquidas.

$\mathrm{Na}$ busca por alimentos, o ácaro O. cynotis lesiona o epitélio do conduto auditivo, levando a uma irritação direta das glândulas ceruminosas e estimulando um aumento na formação de secreção otológica, como observado em 14 $(93,3 \%)$ cães com sarna otodécica. Houve associação $(\mathrm{p}=0,0016)$ entre a presença do ácaro e a produção excessiva de secreção otológica, sendo a prevalência de secreção 1,82 vezes maior em cães infestados do que nos negativos para infestação. Entre os cães parasitados, 1 (6,7\%) tinha secreção amarelada, 1 (6,7\%) esverdeada, 12 (80\%) escurecida (marrom), nenhum apresentou secreção purulenta e 1 $(6,7 \%)$ não tinha secreção (Tab. 1). Estes resultados se assemelham aos relatados por Curtis (2004) e Miller et al. (2013), que comentaram que o conduto auditivo parasitado tipicamente apresenta secreção escura e às vezes endurecida, e que essa coloração provavelmente vem do sangue proveniente da irritação do epitélio. Ainda, o exudato pode mudar de aparência e se tornar purulento, em decorrência de infecção secundária fúngica e/ou bacteriana, deixando o ambiente do conduto impróprio para a sobrevivência dos ácaros. Saridomichelakis et al. (2007) demonstraram resultados próximos aos relatados quando avaliaram 100 cães com otite externa de diferentes etiologias. Dentre estes, sete animais apresentavam otoacaríase com secreção otológica associada, sendo: três (42,9\%) cães com secreção escura semilíquida, um $(14,3 \%)$ com secreção amarelada semilíquida, um $(14,3 \%)$ com secreção ceruminosa, um $(14,3 \%)$ com secreção escura mais endurecida e um $(14,3 \%)$ sem secreção.

Apesar de as secreções otológicas ajudarem na indicação do agente etiológico, as suas características físicas não devem ser usadas como único método diagnóstico etiológico de otites externas em cães, independentemente da causa, sendo sempre fundamental a realização do exame físico completo e outros exames complementares que se fizerem necessários.

Tabela 1. Número de cães examinados segundo diagnóstico para a presença de ácaro Otodectes cynotis e o tipo de secreção otológica. Setor de Dermatologia do Hospital Veterinário de Pequenos Animais da Universidade Federal Rural do Rio de Janeiro

\begin{tabular}{ccccccc}
\hline Infestação & por & \multicolumn{5}{c}{ Tipo secreção otológica } \\
\cline { 2 - 7 } ácaros & Amarelada & Esverdeada & Marrom & Purulenta & Ausente & Total \\
\hline Positivo & 1 & 1 & 12 & 0 & 1 & 15 \\
Negativo & 14 & 4 & 94 & 9 & 114 & 235 \\
Total & 15 & 5 & 106 & 9 & 115 & 250 \\
\hline
\end{tabular}

Através do exame citológico, observou-se que, dentre os animais infestados, nenhum apresentava bactérias nas orelhas direita e esquerda, $7(46,7 \%)$ apresentavam leveduras nas orelhas direita e esquerda, $6(40 \%)$ apresentavam tanto bactérias quanto leveduras nas orelhas direita e esquerda. Em dois (13,3\%) cães não havia microrganismos em suas orelhas direita e esquerda. Houve uma associação $(\mathrm{P}<0,01)$ entre a presença do ácaro $O$. cynotis e a ocorrência de microrganismos nos dois condutos auditivos de cada animal, detectados através da citologia. Estes resultados corroboram os de Mckeever e Torres (1988) e Gotthelf (2007), que afirmaram que o ácaro propicia o aparecimento de infecções bacterianas e/ou fúngicas nos condutos auditivos, e que essas infecções podem ser diagnosticadas através da citologia das secreções 
otológicas, que nos permite detectar a presença de microrganismos, como bactérias, na forma de cocos e bacilos, e leveduras.

Os microrganismos e a quantidade de células por campo observados na citologia de cada uma das orelhas dos animais infestados se encontram relacionados abaixo (Tab. 2).

Girão et al. (2006) sugerem que amostras com 1 a 5 células por campo em objetiva de imersão (+) de Malassezia podem ser encontradas em cães com e sem otite externa. Já 6 a $10(++)$ e > que 10 células por campo em objetiva de imersão $(+++)$ são mais frequentemente coletadas de orelhas com otite, indicando que a levedura pode ter um papel patogênico, ao menos como fator secundário. No presente estudo, dentre os 15 cães com otoacaríase, 24 condutos estavam parasitados e, destes, 16 apresentavam Malassezia $(++)$ ou $(+++)$ na citologia (Tab. 2).

Tabela 2. Avaliação citológica da secreção dos condutos auditivos direito e esquerdo dos cães infestados por Otodectes cynotis examinados no Setor de Dermatologia do Hospital Veterinário de Pequenos Animais da Universidade Federal Rural do Rio de Janeiro

\begin{tabular}{|c|c|c|c|c|}
\hline \multirow{2}{*}{$\begin{array}{c}\text { Cães } \\
\text { infestados } \\
\text { (números de } \\
\text { identificação) }\end{array}$} & \multicolumn{2}{|c|}{$\begin{array}{l}\text { Infestação por } \\
\text { ácaros }\end{array}$} & \multicolumn{2}{|c|}{ Exame citológico } \\
\hline & OD & $\mathrm{OE}$ & OD & $\mathrm{OE}$ \\
\hline 24 & Sim & Sim & Malassezia +++ & Malassezia +++ \\
\hline 31 & Sim & Sim & Cels ep. + & Cels ep. + \\
\hline 35 & Sim & Não & Cocos,+++ Malassezia ++ & Cocos,++ Malassezia +++ \\
\hline 45 & Sim & Sim & Cocos,++ Malassezia ++ & Cocos,++ Malassezia ++ \\
\hline 92 & Sim & Sim & Cocos,++ Malassezia ++ & Cocos,++ Malassezia ++ \\
\hline 101 & Sim & Não & Negativo & Negativo \\
\hline 103 & Sim & Sim & Malassezia,++ Cels ep. ++ & Malassezia,++ Cels ep. ++ \\
\hline 104 & Sim & Sim & Malassezia ++ , Cels ep. ++ & Malassezia ++ , Cels ep. ++ \\
\hline 150 & Sim & Não & Malassezia + & Malassezia + \\
\hline 151 & Sim & Não & Cocos,+ Malassezia + & Cocos,+ Malassezia + \\
\hline 157 & Não & Sim & Malassezia,+ Cocos + & Bacilos,++ cocos +++ \\
\hline 217 & Não & Sim & Cocos,+ Malassezia + & Cocos,+ Malassezia + \\
\hline 224 & Sim & Sim & Malassezia ++ & Malassezia ++ \\
\hline 231 & Sim & Sim & Malassezia ++ & Malassezia ++ \\
\hline 248 & Sim & Sim & Malassezia ++ & Malassezia ++ \\
\hline
\end{tabular}

OD - Orelha direita; OE - Orelha esquerda; Cels ep. - células epiteliais; + até 5 células por campo em objetiva de imersão; ++ de 5 a 10 células por campo em objetiva de imersão; +++ mais de 10 células por campo em objetiva de imersão.

A partir do material coletado dos 500 condutos auditivos dos 250 cães avaliados, foram observados 338 achados citológicos entre microrganismos e células epiteliais de 241 condutos auditivos, tanto hígidos quanto alterados. Os outros 259 condutos apresentaram resultados negativos na citologia (Tab. 3).

A citologia é um método diagnóstico prático e rápido com alta sensibilidade e especificidade, muito útil para a rotina clínica de atendimento dos animais. Sua única limitação é quanto à identificação dos microrganismos, que pode ser necessária especialmente em casos de alterações crônicas dos condutos auditivos (Malayeri et al., 2010).
No exame microbiológico, observou-se que, dentre os animais positivos para o ácaro $O$. cynotis, $11(73,3 \%)$ tinham bactérias em orelhas direitas e $12(80 \%)$ nas esquerdas, $1(6,7 \%)$ tinha leveduras na orelha direita e nenhum tinha levedura na orelha esquerda, $2(13,3 \%)$ tinham tanto bactérias quanto leveduras nas orelhas direita e esquerda. Em um animal (6,7\%) não havia microrganismos em ambos os condutos auditivos. Não houve associação $(p=0,04$ e $\mathrm{p}=0,07$ ) entre a presença do ácaro $O$. cynotis e a ocorrência de microrganismos na cultura das orelhas direita e esquerda, respectivamente. Não existem relatos na literatura consultada sobre a associação entre a presença do ácaro $O$. cynotis e a de microrganismos isolados pelo exame microbiológico de condutos auditivos de cães. 
Tabela 3. Números absoluto e relativo de microrganismos e células encontrados em ambos os condutos auditivos dos cães infestados pelo ácaro e hígidos, através do exame citológico. Setor de Dermatologia do Hospital Veterinário de Pequenos Animais da Universidade Federal Rural do Rio de Janeiro

\begin{tabular}{lcccc} 
Microrganismos & $\begin{array}{c}\mathrm{N}^{0} \text { de cães } \\
\text { infestados }\end{array}$ & $\begin{array}{c}\mathrm{N}^{0} \text { de cães não } \\
\text { infestados }\end{array}$ & Total & $\begin{array}{c}\text { Porcentagem } \\
\text { total }(\%)\end{array}$ \\
\hline Leveduras & 25 & 130 & 155 & 45,86 \\
Cocos & 12 & 51 & 63 & 18,64 \\
Bacilos & 1 & 25 & 26 & 7,69 \\
Células epiteliais & 6 & 80 & 86 & 25,44 \\
Neutrófilos & 0 & 4 & 4 & 1,18 \\
Piócitos & 0 & 3 & 3 & 0,89 \\
Macrófagos & 0 & 1 & 1 & 0,30 \\
Total & 44 & 294 & 338 & 100 \\
\hline
\end{tabular}

Os dados da literatura que avaliam a sensibilidade da citologia e da cultura na detecção de microrganismos são contraditórios. Tater et al. (2003) afirmam que o exame citológico é mais sensível que a cultura na detecção de Malassezia e bactérias, assim como Malayeri et al. (2010), em um estudo comparativo entre as duas técnicas diagnósticas, observaram que $89,91 \%$ dos resultados foram correspondentes, mas em $10,09 \%$ foram detectadas bactérias apenas no exame citológico, o que os leva a indicar uma maior sensibilidade da citologia. No entanto, Girão et al. (2006) demonstraram que $17,8 \%$ e $23,3 \%$ dos animais com e sem otite externa, respectivamente, apresentaram exame citológico negativo e cultura positiva para M. pachydermatis.

No presente estudo, o exame citológico foi capaz de demonstrar maior número de microrganismos nos animais com otoacaríase do que a cultura, mas, ampliando a análise para todos os 500 condutos auditivos avaliados, a cultura detectou um maior número de bactérias e leveduras.

$\mathrm{Na}$ rotina clínica do atendimento de cães, é importante que a interpretação de resultados de exames complementares seja sempre associada aos sinais clínicos demonstrados pelos animais. Não se deve confiar apenas na cultura para a determinação da verdadeira significância de infecções por bactérias e leveduras porque orelhas normais e inflamadas podem albergar os mesmos microrganismos, especialmente em infecções agudas (August, 1988; Ginel et al., 2002).

Os microrganismos mais encontrados nos condutos auditivos dos animais com otoacaríase foram diferentes espécies de Staphylococcus e Bacillus. Os isolamentos realizados através de cultura da secreção otológica dos cães infestados encontram-se relacionados abaixo (Tab. 4).

A partir do material coletado de ambas as orelhas dos 250 cães avaliados, foram isolados 493 microrganismos de 368 condutos auditivos, tanto hígidos quanto alterados. Em 109 foram isolados mais de um microrganismo, enquanto 132 orelhas não tiveram crescimento (Tab. 5).

Alguns microrganismos encontrados no presente estudo são os mesmos isolados por Blot et al. (2003), que avaliaram gatos com otoacaríase e observaram algumas bactérias, como: Staphylococcus intermedius, St. aureus, St. hycius, St. schleiferi, St. caprae, St. simulans, St. xylosus, St. hominis, St. capitis, St. delphini, St. lutrae, St. warneri, St. carnosus, Cellullomonas sp., Corynebacterium sp., Enterococcus sp., Bacillus sp., Streptococcus sp., Aerococcus sp., Acinetobacter sp. e Micrococcus sp., por eles consideradas saprófitas, e dentre as consideradas patogênicas estavam as espécies Str. canis e Commamonas testosteronii.

A avaliação de 500 condutos auditivos clinicamente normais ou com otite revelaram um grande número de estafilococos coagulase negativo, St. aureus aureus, St. intermedius e leveduras. Estes resultados se assemelham aos descritos por outros autores, como Uchida et al. (1990) no Japão, que observou alta prevalência de estafilococos coagulase negativa em cães sadios e com otite externa, assim como Nobre et al. (1998), no Brasil, que também isolaram $M$. pachydermatis, St. intermedius e St. aureus, e ainda Lyskova et al. (2007), na República Tcheca, que encontraram várias espécies de Staphylococcus, além de Str. canis e Bacillus, entre outros, em animais com e sem alterações clínicas nas orelhas. 
Perfil clínico e microbiológico...

Tabela 4. Cães examinados segundo diagnóstico para a presença do ácaro Otodectes cynotis e microrganismos isolados de seus condutos auditivos. Setor de Dermatologia do Hospital Veterinário de Pequenos Animais da Universidade Federal Rural do Rio de Janeiro

\begin{tabular}{|c|c|c|c|c|}
\hline \multirow{2}{*}{$\begin{array}{c}\mathrm{N}^{\mathrm{o}} \text { dos } \\
\text { animais } \\
\text { infestado } \\
\mathrm{S}\end{array}$} & \multicolumn{2}{|c|}{$\begin{array}{l}\text { Infestação por } \\
\text { ácaros }\end{array}$} & \multicolumn{2}{|c|}{ Microrganismos isolados no exame microbiológico } \\
\hline & OD & $\mathrm{OE}$ & OD & $\mathrm{OE}$ \\
\hline 24 & Sim & Sim & Staphylococcus aureus aureus & Staphylococcus intermedius \\
\hline 31 & Sim & Sim & $\mathrm{ECN}$ & $\mathrm{ECN}$ \\
\hline 35 & Sim & Não & $\begin{array}{l}\text { Pseudomonas aeruginosa, } \\
\text { Micrococcus spp. }\end{array}$ & Pseudomonas aeruginosa, Micrococcus spp \\
\hline 45 & Sim & Sim & $\mathrm{ECN}$ & $\mathrm{ECN}$ \\
\hline 92 & Sim & Sim & ECN, Malassezia pachydermatis & $\begin{array}{l}\text { Staphylococcus aureus anaerobius, } \\
\text { Malassezia pachydermatis }\end{array}$ \\
\hline 101 & Sim & Não & Staphylococcus aureus anaerobius & Staphylococcus intermedius \\
\hline 103 & Sim & Sim & Levedura & ECN, Enterobacter spp, Bacillus spp \\
\hline 104 & Sim & Sim & $\mathrm{ECN}$ & $\mathrm{ECN}$ \\
\hline 150 & Sim & Não & Staphylococcus aureus aureus & $\mathrm{ECN}$ \\
\hline 151 & $\operatorname{Sim}$ & Não & $\mathrm{ECN}$ & $\mathrm{ECN}$ \\
\hline 157 & Não & Sim & Pseudomonas spp. & Bacillus spp, ECN \\
\hline 217 & Não & Sim & Staphylococcus intermedius & $\mathrm{ECN}$ \\
\hline 224 & Sim & Sim & Bacillus spp., Levedura & Bacillus spp., Levedura \\
\hline 231 & Sim & Sim & Bacillus spp & Bacillus spp \\
\hline 248 & Sim & Sim & Sem crescimento & Sem crescimento \\
\hline
\end{tabular}

Tabela 5. Microrganismos isolados através do exame microbiológico em ambos os condutos auditivos dos cães infestados pelo ácaro Otodectes cynotis e hígidos. Setor de Dermatologia do Hospital Veterinário de Pequenos Animais da Universidade Federal Rural do Rio de Janeiro

\begin{tabular}{lcccc}
\hline \multicolumn{1}{c}{ Microrganismos } & $\begin{array}{c}\text { Animais } \\
\text { infestados }\end{array}$ & $\begin{array}{c}\text { Animais não } \\
\text { infestados }\end{array}$ & $\begin{array}{c}\text { Total de } \\
\text { isolamentos }\end{array}$ & $\begin{array}{c}\text { Porcentagem } \\
\text { total }(\%)\end{array}$ \\
\hline ECN & 14 & 96 & 110 & 22,31 \\
Bacillus spp. & 6 & 92 & 98 & 19,88 \\
Levedura & 3 & 59 & 62 & 12,58 \\
Staphylococcus aureus aureus & 2 & 36 & 38 & 7,71 \\
Staphylococcus intermedius & 2 & 33 & 35 & 7,1 \\
Staphylococcus spp. & 0 & 28 & 28 & 5,68 \\
Malassezia pachydermatis & 4 & 22 & 26 & 5,27 \\
Micrococcus spp. & 2 & 16 & 18 & 3,65 \\
Staphylococcus schleiferi coagulans & 0 & 14 & 14 & 2,84 \\
Streptococcus canis & 0 & 13 & 13 & 2,64 \\
Staphylococcus aureus anaerobius & 2 & 8 & 10 & 2,03 \\
Pseudomonas spp. & 3 & 7 & 10 & 2,03 \\
Enterobacter spp. & 1 & 9 & 10 & 2,03 \\
Escherichia coli & 0 & 8 & 8 & 1,62 \\
Serratia spp. & 0 & 6 & 6 & 1,22 \\
Streptococcus spp. & 0 & 2 & 2 & 0,4 \\
Proteus mirabilis & 0 & 1 & 1 & 0,2 \\
Morganella moraganii & 0 & 1 & 1 & 0,2 \\
Citrobacter freundii & 0 & 1 & 1 & 0,2 \\
Esporos Clostridium tetani & 0 & 1 & 1 & 0,2 \\
Corynebacteriium spp. & 0 & 454 & 493 & 0,2 \\
Total & 39 & & & 99,99 \\
\hline
\end{tabular}




\section{CONCLUSÕES}

Através do exame citológico, foram observados diferentes microrganismos associados à infestação pelo ácaro O. cynotis. No entanto a cultura não constatou os mesmos resultados. A ocorrência de otite clínica e secreção otológica excessiva, assim como a observação de prurido ótico nos cães pelos proprietários, estiveram associados à presença do ácaro O. cynotis, sugerindo a possibilidade de serem efeito dessa infestação.

\section{REFERÊNCIAS}

AUGUST, J.R. Otitis externa. Vet. Clin. North Am., v.18, p.731-742, 1988.

BLOT, C.; KODJO, A.; REYNAUD, M.C.; BOURDOISEAU, G. Efficacy of selamectin administered topically in the treatment of feline otoacariosis. Vet. Parasit., v.112, p.241-247, 2003.

CDC, EPI INFO 2002. Epidemiology of Program Office. Disponivel em: $<$ http:/www.cdc.gov/epiinfo/index.htm>. Acesso em 07 de abril de 2014.

CHICKERING, W.R. Cytologic evaluation of the otic exudates. Vet. Clin. North Am. Small. Anim. Pract.,v.18, p.773-782, 1988.

CURTIS, C.F. Current trends in the treatment of Sarcoptes, Chyeletiella and Otodectes mite infestations in dogs and cats. Vet. Dermatol., v.15,p.108-114, 2004.

FOLEY, R.H. Parasitic mites of dogs and cats. Comp. Cont Educ. Pract. Vet. ,v.13, p.783-801, 1991.

GINEL, P.J.; LUCENA, R.; RODRIGUEZ, J.C.; ORTEGA, J. A semiquantitative cytological evaluation of normal and pathological samples from the external ear canal of dogs and cats. Vet. Dermatol., v.13, p.151-156, 2002.

GIRÃO, M.D.; PRADO, M.R.; BRILHANTE, R.S.N. et al. Malassezia pachydermatis isolated from normal and diseased external ear canals in dogs: a comparative analysis. Vet. J., v.172, p.544-548, 2006.

GOMES, A.P.M.; NETO, A.F.S.; LOSS, Z.G. et al. Sarna auricular assintomática em cães. Rev. Bras. Med. Vet., v.20, p.175-176, 1998.
GOTTHELF, G.N. (Ed). Doenças do ouvido em pequenos animais. São Paulo: Roca, 2007. 356p.

HOOG, G.S.; GUARRO, J.; GENÉ, J.; FIGUERAS, M.J. Atlas of clinical fungi. Washington: ASM Press, 2000. 1160p.

KONEMAN E.W.; ALLEN S.D.; JANDA W.M.; WINN Jr., W.C. Diagnóstico microbiológico. 6.ed. Rio de Janeiro, Guanabara Koogan, 2008. 1488p

KWOCHKA, K.W. Mites and related disease. Vet. Clin. North Am. Small Anim. Prac., v.17, p.1263-1284, 1987.

LARSSON, C.E. Dermatologia veterinária. I. Dermatites parasitárias dos carnívoros domésticos: sarnas sarcóptica, notoédrica e otoacaríase. Comun. Cient. Fac. Med. Vet. Zootec. Univ. São Paulo, v.13, p.7-17, 1989.

LYSKOVA, P.; VYDRZALOVA, M.; MAZUROVA, J. Identification and antimicrobial susceptibility of bacteria and yeasts isolated from healthy dogs and dogs with otitis externa. J. Vet. Med., v.54, p.559-563, 2007.

MALAYERI, H.Z.; JAMSHIDI, S.; SALEHI, T.Z. Identification and antimicrobial susceptibility patterns of bacteria causing otitis externa in dogs. Vet. Res. Commun., v.34, p.435-444, 2010.

MCKEEVER, P.J.; TORRES, S. Otitis externa, part 1: the ear and predisposing factors to otitis externa. Companion Anim. Pract. Pathophys., v.2, p.7-14, 1988.

MEDLEAU, L.; HNILICA, K.A. (Ed.). Dermatologia de pequenos animais: atlas colorido e guia terapêutico. São Paulo: Roca, 2003. $383 \mathrm{p}$.

MILLER JR, W.H.; GRIFFIN, C.E.; CAMPBELL, K.L. Mueller \& Kirk's small animal dermatology. Philadelphia: Elsevier, 2013. 938p.

NOBRE, M.; MEIRELES, M.; GASPAR, L.F. et al. Malassezia pachydermatis e outros agentes infecciosos nas otites externas e dermatites em cães. Ciênc. Rural, v.28, p.447-452, 1998.

OLIVEIRA， L.C.; LEITE， C.A.L.; BRILHANTE，R.S.N.; CARVALHO, C.B.M. Comparative study of the microbial profile from bilateral canine otitis externa. Can. Vet. J., v.49, p.785-788, 2008. 
OLIVEIRA V.B.; RIBEIRO M.G.; ALMEIDA A.C.S. et al. Etiologia, perfil de sensibilidade aos antimicrobianos e aspectos epidemiológicos na otite canina: estudo retrospectivo de 616 casos. Cienc. Agrar., v.33, p.2367-2374, 2012.

SARIDOMICHELAKIS, M.N.; FARMAKI, R.; LEONTIDES, L.S.; KOUTINAS, A.F. Aetiology of canine otitis externa: a retrospective study of 100 cases. Vet. Dermatol., v.18, p.341-347, 2007.

SOSNA, C.B.; MEDLEAU, L. External parasites: life cycles, transmission and the pathogenesis of disease. Vet. Med., v.6, p.538$547,1992$.

SOUZA, C.P.; SCOTT, F.B.; PEREIRA, M.J.S. Validade e reprodutibilidade da otoscopia e do reflexo otopodal no diagnóstico da infestação por Otodectes cynotis em cães. Rev. Bras. Parasitol. Vet., v.13, p.111-114, 2004.
SOUZA, C.P.; VEROCAI, G.G.; BALBI, M.; SCOTT, F.B. Video otoscopy as a diagnostic tool for canine otoacariasis. Rev. Bras. Parasitol. Vet., v.22, p.440-442, 2013.

TATER, K.C.; SCOTT, D.W.; MILLER JR, W.H.; ERB, H.N. The cytology of the external ear canal in the normal dog and cat. J. Vet. Med., v.50, p.370-374, 2003.

UCHIDA, Y.; NAKADE, T.; KITAZAWA, K. Clinico-microbiological study of the normal and otitic external ear canals in dogs and cats. Jpn. J. Vet. Sci., v. 52, p.415-417, 1990. 